\title{
Ageing the elderly: A new approach to the estimation of the age-at-death distribution from skeletal remains
}

\author{
Clare McFadden (iD | Christine M. Cave (D) | Marc F. Oxenham
}

School of Archaeology and Anthropology, Australian National University, Canberra, ACT, Australia

\section{Correspondence}

Clare McFadden, School of Archaeology and Anthropology, 44 Linnaeus Way, Canberra, ACT 2601, Australia.

Email: clare.mcfadden@anu.edu.au

\begin{abstract}
This study reports on the use of a proportional measure to estimate the age-at-death distribution of an assemblage and, when combined with a seriation method, additionally estimate the age-at-death of individuals. Traditional methods of estimating ageat-death suffer from a number of issues, including decreasing accuracy with increasing age, age mimicry of the reference population, and difficulty balancing accuracy with precision. A new method is proposed for estimating the age-at-death distribution of middle and older adults. As the age-at-death distribution is significantly impacted by the fertility rate, it was hypothesised that the D0-14/D ratio (the number of individuals who died aged 0-14 years divided by the total population; an indicator of fertility) may be able to estimate the proportion of individuals that might be expected to die in each five-year age group over 35 years. The method permits the estimation of individual age when used in conjunction with seriation methods and the age-at-death distribution of a population. The method is tested on two samples of known age, the Spitalfields crypt and St Thomas' Church cemetery collections and found to provide greater accuracy over previously applied methods.
\end{abstract}

\section{KEYWORDS}

age-at-death, D0-14/D ratio, elderly, fertility, mortality

\section{1 | INTRODUCTION}

Age-at-death estimation has applications for both individual and population level investigations in bioarchaeology. Current methods of ageat-death estimation decrease in accuracy with increasing age, due to a higher rate of variability in individual degeneration compared with ontogeny. The ageing process is confounded by a multitude of factors including health, disease, environment, and population and individual variation. Traditional adult age-at-death estimation techniques have sought to identify consistent degenerative changes in known-age populations, such as morphological changes to the pubic symphysis, auricular surface, and sternal rib ends as well as occlusal dental wear, which can be categorised to reflect age brackets and can be applied to the skeletal remains of individuals. When such methods are extrapolated to the population level, age mimicry, a phenomenon whereby populations assume the structure of the known-age sample used to calibrate the age estimation method being applied to them (Bocquet-Appel \& Masset, 1982; Hoppa \& Vaupel, 2002) may occur. Work by Konigsberg and Frankenberg (1992) and Love and Muller (2002) has sought to overcome this. More recently, large scale analyses of tooth (or dental) cementum annulations (TCA) such as Bojarun, Garmus, and Jankauskas (2003), Wittwer-Backofen, Gampe, and Vaupel (2004), and Blondiaux, Alduc-Le Bagousse, Niel, Gabard, and Tyler (2006) have shown promise in precise, individual age-at-death estimation. Notwithstanding, there are some reported limitations in accuracy (Bertrand, Cunha, Bécart, Gosset, \& Hédouin, 2019), such approaches are dependent on the type of microscopy used (Kaur, Astekar, Singh, Arora, \& Bhalla, 2015) and appear to be subject to significant error if non-destructive methods are used (Le Cabec, Tang, Ruano Rubio, \& Hillson, 2019).

Boldsen, Milner, Konigsberg, and Wood (2002) proposed a transition analysis approach to address some of the issues associated with 
individual age estimation, which gives a probability-based age estimate derived from evaluation of several characteristics. However, the method is known to underestimate age from approximately 60 years onwards (Milner \& Boldsen, 2012). As an alternative, Cave and Oxenham (2016) used dental wear seriation (noting that any biologically meaningful method(s) of seriation can be used) and a proxy age-at-death distribution to assign age to individuals over 50 years. Both methods are reliant on the availability and selection of a suitable population distribution: This can be challenging for a number of reasons. A singular modern population experiences different mortality conditions to those of a population in the past. Anthropological populations tend to be small in size and observed for much shorter time periods than the deposition period of a typical skeletal sample (and are therefore more sensitive to short-term fluctuations and instability). The accuracy of historical data can be doubtful due to biased record keeping, for example, religious values may impact the recording of births, stillbirths, miscarriages, and certain causes of death, and census data may be biased against low socioeconomic or marginalized groups (Hollingsworth, 1968; Razzell, 1972).

Gage (1988) promoted the use of competing hazards mortality models and demonstrated the utility of these to palaeodemography through the reanalysis of existing palaeodemographic data. Wood, Holman, O'Connor, and Ferrell (2002) summarised a number of hazard models useful for analysing the age-at-death distribution of past populations, including Gompertz-Makeham, Siler, and mixed-Makeham. These models rely to varying degrees on a general or universally observed trend in the mortality curve. As Wood et al. (2002) observed "the basic pattern of age-specific force of mortality is, in some respects, strikingly similar across a wide range of human populations" (p. 137). They described consistency in the general shape of mortality curve, with high mortality for a few years after birth, a lifetime low at approximately 10-15 years, and then a rise in mortality where the steepness of the rise reflects population-specific mortality conditions, but is typically a steady increase through the 30 s and 40 s, with a sharper increase in the 60s or 70s. To be useful, a mortality model needs to be able to account for variability in the more volatile age groups, specifically the young and elderly (Wood et al., 2002).

This study proposes a new method of estimating age-at-death for individuals over 34 years of age based on the relationship between the rate of fertility and the mortality curve (Bocquet-Appel \& Masset, 1982; Buikstra, Konigsberg, \& Bullington, 1986; Corruccini, Brandon, \& Handler, 1989; Johansson \& Horowitz, 1986; Konigsberg \& Frankenberg, 1994; Sattenspiel \& Harpending, 1983) within a single population. The approach can be combined with any method of seriation (e.g., dental wear and pubic symphysis morphology) in order to more precisely estimate age for individuals over 34 years. Furthermore, the method can be used to estimate the expected proportion of deaths in a series of age categories over 34 years, which may be of interest to evaluate representation, examine the full age at death distribution, and undertake further palaeodemographic investigations. The United Nations have previously undertaken work to regress infant mortality on the age-at-death distribution (Wood et al., 2002). Based on this precedent, and the success of the D0-14/D ratio in estimating fertility and population growth (McFadden \& Oxenham, 2017, 2018), the relationship between this ratio and older age-at-death categories was examined. It is important to note that this method was developed for samples with good preservation and seemingly unbiased subadult representation (e.g., it does not appear that subadults have been differentially interred). Notwithstanding, this study tests the proposed method on the Spitalfields crypt sample, which has been argued to show infant underrepresentation, and the St Thomas' Church cemetery sample.

\section{2 | MATERIALS AND METHODS}

\section{1 | Developing the method}

Two distinct components are reported in this paper: development of the method and validation of the method. The aim of the first component of the research was to develop estimators for the distribution of elderly adults into discrete age categories. For this component of the study, data from the United Nations (2019) database were used (all data are provided in Table S1). As per discussions in McFadden and Oxenham $(2017,2018)$ modern data have been used in order to overcome issues with model life table, historical, and anthropological data. Specifically, model life tables suffer from the assumption of stationarity and from logical circularity, in that, the distribution of the life table is calculated based on inputs of fertility and mortality, and thus, variables are not independent (Corruccini et al., 1989; Milner, Wood, \& Boldsen, 2007; Moore, Swedlund, \& Armelagos, 1975; Sattenspiel \& Harpending, 1983; Weiss \& Wobst, 1973; Wood et al., 1992). With regard to historical data, the accuracy of such data is difficult to estimate. Many of these data are taken from parish records, where sociocultural biases may occur (Hollingsworth, 1968; Razzell, 1972). Anthropological data are reasonably scarce, tend to reflect short time periods, and are not necessarily an improved representation of past conditions. The use of modern data permits the inclusion of a larger number of nonstationary populations over the course of several years. Furthermore, the aim is not to find data that replicate past levels of fertility and mortality, but rather that reflect a sufficient range of variation to demonstrate a consistent and robust relationship between the variables of interest.

There has been much speculation about the life expectancy of past populations, but it is broadly accepted that it would be much lower than today due to the impacts of higher fertility, higher rates of infant mortality, and less capability for care and medical intervention for agerelated illnesses and senescence. As observed by Sattenspiel and Harpending (1983), amongst others (e.g., Bocquet-Appel \& Masset, 1982; Buikstra et al., 1986; Corruccini et al., 1989; Johansson \& Horowitz, 1986; Konigsberg \& Frankenberg, 1994), fertility in particular has significant impacts on the age-at-death distribution. Countries with high life expectancy in the present, such as Japan where it is over 84 years (the World Bank, 2019), are influenced by both low fertility rates and life-prolonging care for the elderly. Evaluating life expectancy at age 20 years instead of at birth in part overcomes the 
influence of fertility, but such data are scarce. Samples with life expectancy at birth under 55 years and dating to 1960 or prior (due to the influence of the contraceptive pill) were selected for inclusion. Life expectancy was taken from the World Bank data (2019). Countries meeting this requirement and for which sufficient data were available were Egypt, El Salvador, Fiji, Guatemala, and Sao Tome and Principe. Data were available for individual years spanning 1948-1960, and a total of 49 samples were identified for inclusion. Although having the potential to be a better proxy for past populations, further reducing the life expectancy cut-off point was not viable as insufficient data were available.

Data cleaning was performed by checking and where necessary amending totals based on the sum of each reported age category. The data were also examined for anomalies and concerns. It was noted that the small population sizes of Fiji and Sao Taome and Principe may introduce greater volatility, but that would be of significant interest due to the intended application to small populations (although, as previously noted, which span much longer time periods than the annual modern data). To test for autocorrelation, DurbinWatson tests were undertaken on each country grouping with data for more than 1 year.

The D0-14/D ratio was calculated as the number of individuals who died aged 0-14 years divided by the total number of deaths. The outputs to be estimated were the percentage of all deceased individuals that we would expect to fall into each 5-year interval over 34 years. This cut-off was selected as the primary aim of the method was to improve the estimation of age for middle (35-50 years) and old (50 + years) adults as defined by Buikstra and Ubelaker (1994). In order to be useful in conjunction with seriation methods of age-atdeath estimation, such as applied by Cave and Oxenham (2016), an estimator for the number of individuals aged 15-34 years was also calculated. The number of individuals who died within each 5-year age interval over 34 years (e.g., 34-39 years, 40-44 years up to 7074 years) was divided by the total number of deaths to give a percentage of all deaths that occurred in each interval. Linear regression was used to model the relationship.

\section{2 | Validating the method}

The second component of the study sought to test the method on samples of known age-at-death to evaluate the accuracy of the method. Data for the Spitalfields crypt collection were extracted from Cox (1996), and data from the St Thomas' Church cemetery collection were taken from Saunders et al. (2002). Using the DO$14 / D$ ratio for this population, the number of individuals in each 5 -year age group was calculated. Additionally, based on comments by Cox (1996), which suggested infants may have been underrepresented in the Spitalfields collection, an underestimation model was also calculated where the D0-14/D was artificially set to 0.35 . This level was selected arbitrarily to demonstrate the impacts of a moderately higher fertility rate on the age-at-death distribution. The estimated distribution of individuals based on the known-age-derived D0-14/D ratio, and for Spitalfields an additional underestimation scenario, was compared with the distribution based on known ageat-death records by calculating the proportion of correctly classified individuals for both samples.

\section{3 | RESULTS}

\section{1 | Regression equations for the age-at-death distribution}

Using the equations derived from the $<55$-years life expectancy samples, the D0-14/D ratio can reasonably estimate the proportion of individuals in a single population who died in each interval from 3539 years through to $70-74$ years, but ceased to be accurate after this point. The correlations and linear regression equations are reported in Table 1. Scatter plots are provided in Figures S1-S10.

It was noted that the high correlations between the D0-14/D ratio and proportion of deaths observed for most age groups might be influenced by the distribution of the data. In some scenarios, Egypt ( $n=13$ years) and Fiji ( $n=12$ years) form separate clusters of results at the ends of the observed distribution. Separate estimates of these correlations were calculated for Egypt and Fiji. It was anticipated that these estimates would suffer from restriction of range in the two subsamples. To address this issue, correlations were adjusted using Thorndike's correction for restriction of range (Thorndike, 1949). United Nations (2019) data for the year 2000 were used to estimate the population standard deviation. Separate sample standard deviations were calculated for Egypt and Fiji. As expected, both the standard deviation and the uncorrected correlations between mortality ratio and proportion of deaths were reduced in the Egypt and Fiji subsamples. The results corrected for restriction of range yielded correlations that were broadly consistent with those for the sample as a whole (Table 2).

Autocorrelation was tested for using the Durbin-Watson test. The results of these tests are reported in Table 3. Durbin-Watson test

TABLE 1 Correlations and regression equations for D0-14/D and the age-at-death categories of interest

\begin{tabular}{|lll}
$\begin{array}{l}\text { Age-at-death } \\
\text { interval in years }\end{array}$ & $<55$ years $(r)$ & $<55$-year linear regression equations \\
\hline $15-34$ & -0.409 & $y=-0.1117 x+0.1580$ \\
\hline $35-39$ & -0.464 & $y=-0.0231 x+0.0378$ \\
\hline $40-44$ & -0.569 & $y=-0.0295 x+0.0418$ \\
\hline $45-49$ & -0.731 & $y=-0.0427 x+0.0487$ \\
\hline $50-54$ & -0.904 & $y=-0.0479 x+0.0569$ \\
\hline $55-59$ & -0.832 & $y=-0.0699 x+0.0644$ \\
\hline $60-64$ & -0.971 & $y=-0.2117 x+0.1623$ \\
\hline $65-69$ & -0.966 & $y=-0.1207 x+0.0981$ \\
\hline $70-74$ & -0.923 & $y=-0.2181 x+0.1638$ \\
\hline $75+$ & -0.334 & $y=-0.1061 x+0.1569$ \\
\hline
\end{tabular}

Note. $p<.05$ for all correlations, where $\mathrm{x}$ is the D0-14/D ratio 
TABLE 2 Uncorrected and restriction of range corrected correlations for Egypt and Fiji

\begin{tabular}{|llllll|}
$\begin{array}{lllll}\text { Age-at- } \\
\text { death } \\
\text { interval } \\
\text { in years }\end{array}$ & $\begin{array}{lllll}\text { Egypt } \\
\text { uncorrected }\end{array}$ & $\begin{array}{l}\text { Egypt } \\
\text { corrected } \\
\text { for } \\
\text { restriction } \\
\text { of range }\end{array}$ & $\begin{array}{l}\text { Fiji } \\
\text { uncorrected }\end{array}$ & $\begin{array}{l}\text { restriction } \\
\text { of range }\end{array}$ & $\begin{array}{l}\text { Whole } \\
\text { somple }\end{array}$ \\
\hline $15-34$ & -0.419 & -0.752 & -0.414 & -0.487 & -0.409 \\
\hline $35-39$ & -0.631 & -0.951 & -0.218 & -0.488 & -0.464 \\
\hline $40-44$ & -0.529 & -0.866 & -0.397 & -0.735 & -0.569 \\
\hline $45-49$ & -0.713 & -0.994 & -0.190 & -0.561 & -0.731 \\
\hline $50-54$ & -0.852 & -0.997 & -0.249 & -0.730 & -0.904 \\
\hline $55-59$ & -0.373 & -0.835 & -0.299 & -0.900 & -0.832 \\
\hline $60-64$ & -0.942 & -0.999 & -0.242 & -0.507 & -0.971 \\
\hline $65-69$ & -0.191 & -0.656 & -0.685 & -0.994 & -0.966 \\
\hline $70-74$ & -0.650 & -0.997 & -0.140 & -0.582 & -0.923 \\
\hline
\end{tabular}

TABLE 3 Results of Durbin-Watson tests for autocorrelation

\begin{tabular}{|lll|}
\hline Country & Number of years included & Durbin-Watson tests \\
\hline Fiji & 12 & $1.53-3.01$ \\
\hline Egypt & 13 & $1.75-3.08$ \\
\hline El Salvador & 13 & $0.88-3.44$ \\
\hline Guatemala & 10 & $1.36-2.89$ \\
\hline
\end{tabular}

results of 2 suggest no autocorrelation, whereas a result of over 2 suggests negative autocorrelation (Field, 2009). Scores of less than 1 are considered indicative of significant positive autocorrelation, and scores greater than 3 are indicative of significant negative autocorrelation (Field, 2009). In many cases, moderate negative autocorrelation was found, which indicates the regression model may in fact be underestimating the strength of the relationship (Field, 2009). One of the total of 36 Durbin-Watson tests produced a score below 1 (for El Salvador for the age group 65-69=0.88), but all other tests exceeded 1. Three tests exceeded a score of 3, being Fiji for 35-39, Egypt for 50-54, and El Salvador 50-54.

Sattenspiel and Harpending (1983) observed that the age-at-death distribution is more sensitive to changes in fertility than mortality. The correlations between the D0-14/D ratio and the age-at-death categories proposed in this study are believed to be the result of the influence fertility has on the age-at-death distribution and the use of a closed proportion, where the estimation of one component of the proportion contributes to the accuracy of estimating other components of the proportion. The correlations are reported, and logical explanation support the application of the sample results to actual data derived from skeletal samples.

Ideally, samples with various average ages at death would be analysed; however, accurate data are typically only available for industrialised populations, where the life expectancy is higher than what we may expect in pre-industrial populations. In industrialised populations, those with a low life expectancy often experience conditions that are not conducive for accurate and frequent census data collection (e.g., due to warfare, poor socioeconomic conditions, small population size/low density, etc.). Monte Carlo simulations may be used in the future to address this issue.

\section{2 | Validation on Spitalfields and St Thomas' Church samples}

The equations derived from the $<55$-year life expectancy samples were subsequently applied to skeletal samples of known age-at-death in order to evaluate the application of the method and its accuracy in the intended context. A worked example of how to apply the method is provided in supporting information Figure S11 and Table S2. The method was applied to data from the Spitalfields crypt collection (Cox, 1996) and St Thomas' Church cemetery sample (Saunders et al., 2002), both of which had known age-at-death data and were well-suited to testing the accuracy of the method. Cox (1996) suggested that infants were underrepresented at Spitalfields based on historical records, which reported a higher proportion of infant deaths. As such, the estimated distribution based on the D0-14/D from the known age-at-death data (0.22) and an underestimation scenario of higher D0-14/D ratio (0.35) were calculated for Spitalfields. For St Thomas' Church cemetery, adult age-at-death had been estimated using the pubic symphysis and auricular surface (Saunders et al., 2002), which afforded the opportunity for comparison. Based on the skeletal remains for St Thomas' Church cemetery, a D0-14/D ratio of 0.54 was calculated.

The results for both samples were compared based on the proportion of correctly classified individuals. Applying the method proposed in this study to the Spitalfields crypt-calculated D0-14/D ratio resulted in $81 \%$ of individuals being correctly classified, whereas the underestimation scenario correctly classified $83 \%$ of individuals (Table 4). As the

TABLE 4 Comparison of results for known age and estimated age distributions for Spitalfields

\begin{tabular}{|c|c|c|c|c|c|}
\hline \multirow[b]{2}{*}{$\begin{array}{l}\text { Age-at- } \\
\text { death } \\
\text { interval }\end{array}$} & \multirow{2}{*}{$\begin{array}{l}\text { Spitalfields } \\
\text { known } \\
\text { age-at- } \\
\text { death }\end{array}$} & \multicolumn{2}{|c|}{ Estimated distribution } & \multicolumn{2}{|c|}{ Incorrectly classified } \\
\hline & & $\begin{array}{l}\text { Crypt } \\
\text { D0- } \\
\text { 14/D }\end{array}$ & $\begin{array}{l}\text { Underestimate } \\
\text { D0-14/D }\end{array}$ & $\begin{array}{l}\text { Crypt } \\
\text { D0- } \\
\text { 14/D }\end{array}$ & $\begin{array}{l}\text { Underestimate } \\
\text { D0-14/D }\end{array}$ \\
\hline $15-34$ & 43 & 50 & 44 & 7 & 1 \\
\hline $35-39$ & 18 & 12 & 11 & 6 & 7 \\
\hline $40-44$ & 11 & 18 & 19 & 7 & 8 \\
\hline $45-49$ & 23 & 15 & 13 & 8 & 10 \\
\hline $50-54$ & 30 & 17 & 15 & 13 & 15 \\
\hline $55-59$ & 25 & 18 & 15 & 7 & 10 \\
\hline $60-64$ & 31 & 43 & 33 & 12 & 2 \\
\hline $65-69$ & 28 & 27 & 21 & 1 & 7 \\
\hline $70-74$ & 35 & 43 & 33 & 8 & 2 \\
\hline \multicolumn{4}{|c|}{ Total misclassified } & 69 & 62 \\
\hline \multicolumn{4}{|c|}{ Percentage incorrectly classified } & $19 \%$ & $17 \%$ \\
\hline \multicolumn{4}{|c|}{ Percentage correctly classified } & $81 \%$ & $83 \%$ \\
\hline
\end{tabular}


underestimation scenario provided a slight improvement over the crypt-derived D0-14/D calculation (although not a statistically significant one), the results may lend support to Cox's (1996) assertion that infants are underrepresented; although other sources of evidence would be needed to confirm this.

Applying the method to the St Thomas' Church cemetery sample produced similarly promising results, however, highlighted an unusual mortality peak in young adulthood (Table 5). Based on this, our method showed an improvement over traditional methods (82\% vs. $73 \%$ correctly classified). As the method is intended primarily for age estimation for older adults, excluding the 15-34-year age group improves the accuracy of our method to $90 \%$ correctly classified.

\section{4 | DISCUSSION}

The method proposed here is detecting the influence of fertility on the age-at-death distribution (Bocquet-Appel \& Masset, 1982; Buikstra et al., 1986; Corruccini et al., 1989; Johansson \& Horowitz, 1986; Konigsberg \& Frankenberg, 1994; Sattenspiel \& Harpending, 1983) and tells us little about changes in mortality. Using the D0-14/D ratio as the basis of the age-category calculations means that the estimates produced from this method and those for fertility and rate of natural population increase are detecting the same changes in the age-atdeath distribution. However, the fertility and rate of natural population increase measures are for a distinctly different purpose to distributing the individuals aged over 35 years; the method proposed in this study is intended to facilitate further investigations into the health, disease, and sociocultural status of older individuals. The method is based on a very generalised empirical model of mortality derived from modern populations with low life expectancy. The generalised nature of the model supports its application in a range of contexts, but notably, this means the model does not accommodate all sources of variability and

TABLE 5 Comparison of results for known age, traditional estimated, and our estimated age distribution for St Thomas' Church cemetery

\begin{tabular}{|c|c|c|c|c|c|}
\hline \multirow[b]{2}{*}{$\begin{array}{l}\text { Age-at- } \\
\text { death } \\
\text { interval }\end{array}$} & \multirow{2}{*}{$\begin{array}{l}\text { St } \\
\text { Thomas' } \\
\text { Church } \\
\text { known } \\
\text { age-at- } \\
\text { death }\end{array}$} & \multicolumn{2}{|c|}{ Estimated distribution } & \multicolumn{2}{|c|}{ Incorrectly classified } \\
\hline & & $\begin{array}{l}\text { Traditional } \\
\text { methods }\end{array}$ & $\begin{array}{l}\text { D0-14/D } \\
\text { estimate }\end{array}$ & $\begin{array}{l}\text { Traditional } \\
\text { methods }\end{array}$ & $\begin{array}{l}\text { D0-14/D } \\
\text { estimate }\end{array}$ \\
\hline $15-34$ & 18 & 11 & 10 & 7 & 8 \\
\hline $35-39$ & 4 & 7 & 3 & 3 & 1 \\
\hline $40-44$ & 4 & 6 & 6 & 2 & 2 \\
\hline $45-49$ & 4 & 8 & 3 & 4 & 1 \\
\hline $50-54$ & 4 & 5 & 3 & 1 & 1 \\
\hline $55-59$ & 4 & 4 & 3 & 0 & 1 \\
\hline $60+$ & 16 & 6 & 13 & 10 & 3 \\
\hline \multicolumn{4}{|c|}{ Total misclassified } & 27 & 18 \\
\hline \multicolumn{4}{|c|}{ Incorrectly classified } & $27 \%$ & $18 \%$ \\
\hline \multicolumn{4}{|c|}{ Correctly classified } & $73 \%$ & $82 \%$ \\
\hline
\end{tabular}

offers a somewhat reductive approach to the age-at-death distribution. These limitations should be noted when using the method. Comparison with other mortality models and age-estimation methods may validate the suitability and accuracy of this model; however, all methods are subject to different assumptions and potential sources of error.

This study has provided a simple means of estimating the distribution of the elderly in a single population based on the general shape of the mortality curve. Each equation estimates the percentage of the total deceased population (e.g., cemetery sample) that is likely to have died during each 5-year interval based on the D0-14/D ratio. The estimates will only be as accurate as the D0-14/D input, and as such, this method is not suitable for samples with poor preservation or differential burial of subadults. Furthermore, the method will only be accurate under normal mortality conditions and should not be used where catastrophic mortality (for example, the plague) is inferred; as previously noted, it is not sensitive to significant changes in mortality.

The method used to derive our model was based on available data, noting some limitations due to accurate census data being frequently unavailable for low life expectancy populations. The use of historical data was deliberately avoided due to concerns about bias and inaccuracy (Hollingsworth, 1968; Razzell, 1972). Steps were taken to address some of the major issues with the data utilised, especially restriction of range. We believe that the process of model development was sufficiently strong to justify its application to skeletal data. We were mindful of the need to avoid overanalysis of our base data, noting the much quoted observation of R. H. Coase that "if you torture the data long enough, it will confess" (1981). Ultimately, the application of our model to the Spitalfields and St Thomas' Church data reinforces its ability to accurately estimate the distribution of older individuals, while highlighting some of the weaknesses of the method. The known-age derived D0-14/D ratio (0.22) and the underestimation scenario of an increased D0-14/D ratio (0.35) correctly classified $81 \%$ and $83 \%$ of Spitalfields individuals. Although minimal, the improved accuracy under the artificially increased D0-14/D ratio scenario may support Cox's (1996) suggestion that infants are underrepresented in the Spitalfields crypt collection but further evidence is needed. For the St Thomas' Church sample, the method produced a more accurate result than the previously performed age-at-death estimation based on the pubic symphysis and auricular surface. Noting the unusual mortality peak in young adults in this sample, our method showed even greater accuracy when it was applied only to the individuals it was intended for (i.e., the middle and older adults). Based on these two applications, we believe the proposed method provides greater precision and accuracy over current age-at-death distribution methods. A clear advantage of this method over many traditional approaches is its ability to disaggregate the $50+$ or elderly age category and assign age up to 75 years. It is yet to be compared with more complex methods such as Boldsen et al. (2002).

The method can be applied to any assemblage that has been appropriately seriated, including dental wear, pubic symphyseal morphology, cranial suture closure, or any combination of methods. The Cave and Oxenham (2016) method for identifying older individuals 
in a cemetery sample is based on the idea that ancient communities, like those today, would have had a predictable age structure and that a percentage of individuals from such communities would have lived to their 70s, 80s, or beyond (Chamberlain, 1997). This idea is supported by the work of Gurven and Kaplan (2007) who studied extant peoples who live traditional lives away from modern medicine, markets, and other cultural buffers alongside a greater possibility of being subject to environmental adversity. They found similar mortality profiles across the studied populations, which encompassed people from differing environments participating in different ways of life (Gurven \& Kaplan, 2007). Individuals remained vital and resilient until senescence set in, presaging death in the not too distant future (Gurven \& Kaplan, 2007). The modal age of death across these populations was about 70 years suggesting a characteristic life span that evolved with the species (Gurven \& Kaplan, 2007).

The ageing method in Cave and Oxenham (2016) involves seriating toothwear scores of all adult individuals from the subject population from least worn to most worn. Toothwear is useful because it is both continuous throughout life and unidirectional, but care needs to be taken that the method is used on a community without evidence of differential eating practices between age cohorts, status groups, sexes, or over time (Buckberry, 2015); malocclusion, loss of occlusal partners, and the possible use of teeth as tools are also possible confounding factors that need to be identified and if necessary, compensated for In the first iteration of the method, individuals are seriated then placed within a model population of similar structure to the archaeological population, taking into account the biases inherent in skeletal ageing, which tend to underage the elderly. The choice of this population is a key aspect of this method and until now, has relied on historical mortality databases, which appear to fit the target community. This has been done by comparison of the population structures by eye, rather than using mathematical or statistical rigour. The choice of model is an essential part of the process which will create the structure of the population and reflects environmental factors, cultural, and personal practices of the inhabitants. By combining the seriation approach with the new method proposed here, the actual demographic structure of the population is used to distribute the older individuals rather than attempting to replicate the structure by proxy.

In addition to its utility in conjunction with seriation methods, the estimators can be applied in the absence of such information and may still provide valuable insights into the population distribution. Where preservation does not permit seriation or where seriation is impractical, but the calculation of the D0-14/D ratio is still possible, the method can be applied to estimate the number of individuals that died in each 5-year age group, and the population distribution can be inferred. In this way, the estimators may provide both ages-at-death for individuals of interest when used in combination with seriation methods and also provide the age-at-death distribution for the older portion of the population of interest. The former is expected to be beneficial for traditional bioarchaeological studies and palaeoepidemiology, whereas the latter may be particularly useful for palaeodemographic research. A worked example of the method is provided in the supporting information.

\section{5 | CONCLUSION}

This method adds to a suite of estimators derived from the D0-14/D ratio. The interdependency of such outputs is not a concern in this case, as the ultimate intention of the method is to learn more about the lives of the elderly in past populations. Indeed, the method is based on the influence of fertility, represented by the D0-14/D ratio, on the population structure. Adult and particularly elderly, age-atdeath estimation continues to be a significant challenge in bioarchaeological studies. Although the method requires further testing and calibration on a greater range of data, particularly with regard to life expectancy at birth in the populations studied, it offers significant advantages over existing methods of distributing the elderly, which require selection of suitable proxy populations. Although some limitations have been noted, the method has been subjected to substantial statistical rigour, and its accuracy when applied to the data from the Spitalfields crypt and St Thomas' Church is particularly reassuring. As a preliminary study, using the D0-14/D ratio to predict the distribution of elderly individuals has shown promising results and proven accessibility and ease of application of the method. Future research may seek to refine the method through the use of Monte Carlo simulations and may also test a variety of other regression models.

\section{ACKNOWLEDGEMENTS}

Thank you to the anonymous reviewers for their feedback which undoubtedly improved this manuscript.

\section{ORCID}

Clare McFadden (I) https://orcid.org/0000-0002-9515-5392

Christine M. Cave (D) https://orcid.org/0000-0001-6789-9063

Marc F. Oxenham (D) https://orcid.org/0000-0002-5804-2145

\section{REFERENCES}

Bertrand, B., Cunha, E., Bécart, A., Gosset, D., \& Hédouin, V. (2019). Age at death estimation by cementochronology: Too precise to be true or too precise to be accurate? American Journal of Physical Anthropology, 169, 464-481.

Blondiaux, J., Alduc-Le Bagousse, A., Niel, C., Gabard, N., \& Tyler, E. (2006). Relevance of cement annulations to paleopathology. Paleopathology Newsletter, 135, 4-15.

Bocquet-Appel, J. P., \& Masset, C. (1982). Farewell to paleodemography. Journal of Human Evolution, 11(4), 321-333.

Bojarun, R., Garmus, A., \& Jankauskas, R. (2003). Microstructure of dental cementum and individual biological age estimation. Medicina, 39(10), 960-964.

Boldsen, J., Milner, G., Konigsberg, L., \& Wood, J. (2002). Transition analysis: A new method for estimating age from skeletons. In R. D. Hoppa, \& J. W. Vaupel (Eds.), Paleodemography: Age distributions from skeletal samples (pp. 73-106). Cambridge: Cambridge University Press.

Buckberry, J. (2015). The (mis)use of adult age estimates in osteology. Annals of Human Biology, 42, 323-331.

Buikstra, J. E., Konigsberg, L. W., \& Bullington, J. (1986). Fertility and the development of agriculture in the prehistoric Midwest. American Antiquity, 51(3), 528-546. 
Buikstra, J. E., \& Ubelaker, D. H. (1994) Standards for data collection from human skeletal remains.

Cave, C., \& Oxenham, M. F. (2016). Identification of the archaeological 'invisible elderly': An approach illustrated with an Anglo-Saxon example. International Journal of Osteoarchaeology, 26(1), 163-175.

Chamberlain, A. T. (1997). Commentary: Missing stages of life-Towards the perception of children in archaeology. In J. Moore, \& E. Scott (Eds.), Invisible people and processes: Writing gender and childhood into European archaeology (pp. 203-212). London and New York: Leicester University Press.

Coase, R. H. (1981) "How should economists choose?" Warren Nutter Lecture.

Corruccini, R., Brandon, E., \& Handler, J. (1989). Inferring fertility from relative mortality in historically controlled cemetery remains from Barbados. American Antiquity, 54(3), 609-614.

Cox, M. (1996). Life and death in Spitalfields, 1700 to 1850. York: Council for British Archaeology.

Field, A. P. (2009). Discovering statistics using SPSS: (and sex, drugs and rock'n'roll). London: Sage Publications.

Gage, T. (1988). Mathematical hazard models of mortality: An alternative to model life tables. American Journal of Physical Anthropology, 76, 429-441.

Gurven, M., \& Kaplan, H. (2007). Longevity among hunter-gatherers: A cross-cultural examination. Population and Development Review, 33, 321-365.

Hollingsworth, T. H. (1968). The importance of the quality of the data in historical demography. Daedalus, 1, 415-432.

Hoppa, R. D., \& Vaupel, J. W. (Eds.) (2002). Paleodemography: Age distributions from skeletal samples. Cambridge: Cambridge University Press.

Johansson, S. R., \& Horowitz, S. (1986). Estimating mortality in skeletal populations: Influence of the growth rate on the interpretation of levels and trends during the transition to agriculture. American Journal of Physical Anthropology, 71(2), 233-250.

Kaur, P., Astekar, M., Singh, J., Arora, K. S., \& Bhalla, G. (2015). Estimation of age based on tooth cementum annulations: A comparative study using light, polarized, and phase contrast microscopy. Journal of Forensic Dental Sciences, 7, 215-221.

Konigsberg, L. W., \& Frankenberg, S. R. (1992). Estimation of age structure in anthropological demography. American Journal of Physical Anthropology, 89(2), 235-256.

Konigsberg, L. W., \& Frankenberg, S. R. (1994). Paleodemography: "Not quite dead". Evolutionary Anthropology, 3, 92-105.

Le Cabec, A., Tang, N. K., Ruano Rubio, V., \& Hillson, S. (2019). Nondestructive adult age at death estimation: Visualizing cementum annulations in a known age historical human assemblage using synchrotron X-ray microtomography. American Journal of Physical Anthropology, 168, 25-44.

Love, B., \& Muller, H. G. (2002). A solution to the problem of obtaining a mortality schedule for paleodemographic data. In R. D. Hoppa, \& J. W. Vaupel (Eds.), Paleodemography: Age distributions from skeletal samples (pp. 181-192). Cambridge: Cambridge University Press.

McFadden, C., \& Oxenham, M. F. (2017). The D0-14/D ratio: A new paleodemographic index and equation for estimating total fertility rates. American Journal of Physical Anthropology, 165(3), 471-479.
McFadden, C., \& Oxenham, M. F. (2018). Rate of natural population increase as a paleodemographic measure of growth. Journal of Archaeological Science: Reports, 19, 352-356.

Milner, G. R., \& Boldsen, J. L. (2012). Transition analysis: A validation study with known-age modern American skeletons. American Journal of Physical Anthropology, 148(1), 98-110.

Milner, G. R., Wood, J. W., \& Boldsen, J. L. (2007). Advances in paleodemography. In Biological anthropology of the human skeleton (pp. 561-600). Hoboken, NJ: John Wiley \& Sons, Inc.

Moore, J. A., Swedlund, A. C., \& Armelagos, G. J. (1975). The use of life tables in paleodemography. Memoirs of the Society for American Archaeology, 30, 57-70.

Razzell, P. E. (1972). The evaluation of baptism as a form of birth registration through cross-matching census and parish register data: A study in methodology. Population Studies, 26(1), 121-146.

Sattenspiel, L., \& Harpending, H. (1983). Stable populations and skeletal age. American Antiquity, 48(3), 489-498.

Saunders, S. R., Herring, A., Sawchuk, L., Boyce, G., Hoppa, R., \& Klepp, S. (2002). The health of the middle class: The St. Thomas' Anglican Church cemetery project. In R. Steckel, \& J. C. Rose (Eds.), The backbone of history: Health and nutrition in the Western Hemisphere. Cambridge: Cambridge University Press.

The World Bank (2019) Databank. Available from https://data.worldbank. org/

Thorndike, R. L. (1949). Personnel selection: Test and measurement techniques. New York: Wiley.

United Nations (2019) UNSD Statistical Database. Available from https:// unstats.un.org/unsd/databases.htm

Weiss, K. M., \& Wobst, H. M. (1973). Demographic models for anthropology. Memoirs of the Society for American Archaeology, 27, i-186.

Wittwer-Backofen, U., Gampe, J., \& Vaupel, J. W. (2004). Tooth cementum annulation for age estimation: Results from a large known-age validation study. American Journal of Physical Anthropology, 123, 119-129.

Wood, J. W., Holman, D. J., O'Connor, K. A., \& Ferrell, R. J. (2002). Mortality models for paleodemography. In R. D. Hoppa, \& J. W. Vaupel (Eds.), Paleodemography: Age distributions from skeletal samples (pp. 129-168). Cambridge: Cambridge University Press.

Wood, J. W., Milner, G. R., Harpending, H. C., Weiss, K. M., Cohen, M. N., Eisenberg, L. E., ... Wilkinson, R. G. (1992). The osteological paradox: Problems of inferring prehistoric health from skeletal samples [and Comments and Reply]. Current Anthropology, 33(4), 343-370.

\section{SUPPORTING INFORMATION}

Additional supporting information may be found online in the Supporting Information section at the end of the article.

How to cite this article: McFadden C, Cave C, Oxenham MF. Ageing the elderly: A new approach to the estimation of the age-at-death distribution from skeletal remains. Int $J$ Osteoarchaeol. 2019;29:1072-1078. https://doi.org/10.1002/ oa. 2820 